\title{
Susceptibility to Multiple Sclerosis is Associated with the Proximal Immunoglobulin Heavy Chain Variable Region
}

Michael A. Walter, William T. Gibson, George C. Ebers, ${ }^{\star}$ and Diane W. Cox

Research Institute, The Hospital for Sick Children and Departments of Paediatrics and Medical Genetics, University of Toronto, Toronto, Ontario, Canada; and *Department of Clinical Neurological Sciences, University Hospital, University of Western Ontario, London, Ontario, Canada M5G IX8

\begin{abstract}
15 immunoglobulin heavy chain constant $(\mathrm{CH})$ and variable region (VH) polymorphisms were selected to span the entire length of the heavy chain cluster. These polymorphisms were examined in 34 sib pairs concordant for multiple sclerosis (MS) and in 23 sporadic MS patients. Allele frequencies were calculated for the 2 MS patient groups and compared with those found in a control population from the same geographical location and of similar ethnic background. No significant association was found between $\mathrm{MS}$ and the $7 \mathrm{CH}$ region polymorphisms examined. However, a significant correlation between the MS phenotype and a VH2 family polymorphism was observed in both MS patient populations (familial MS patients $\chi^{2}$ $=8.16, P<0.005 ;$ sporadic MS patients $\left.\chi^{2}=8.90, P<0.005\right)$. One allele of the VH2-5 gene segment was found to be overrepresented in both MS groups. VH2-5 has recently been physically mapped close to the $\mathrm{CH}$ region, between 180 and $360 \mathrm{~kb}$ away. These results indicate that a locus near or within the CH-proximal VH region is associated with increased susceptibility to MS. (J. Clin. Invest. 1991. 87:1266-1273.) Key words: MS • VH • disease association • polymorphism • VH2
\end{abstract}

\section{Introduction}

Multiple sclerosis (MS) ${ }^{1}$ is the most common chronic disease of the CNS affecting young adults, with a prevalence of $\sim 60$ per 100,000 in the Northern United States (1) and of over 100 per 100,000 in Canada (2). MS has a predilection for whites of Northern European descent. Patients commonly experience loss of vision, weakness, numbness, and impairment of coordination, among other symptoms (3). These effects may be traced to impairment of the CNS white matter tracks which is itself secondary to the loss of myelin sheath with relative axonal preservation.

Familial aggregation of MS has been demonstrated $(4,5)$. The higher concordance rates in monozygotic twins than in

Address correspondence and reprint requests to Dr. D. W. Cox, 555 University Avenue, Toronto, Ontario, Canada M5G 1 X8. 1990

Received for publication 16 July 1990 and in revised form 28 August

1. Abbreviations used in this paper: $\mathrm{CH}$, immunoglobulin heavy chain constant region; IGH, immunoglobulin heavy chain; EAE, experimental allergic encephalomyelitis; HLA, human leukocyte antigen; MBP, myelin basic protein; MS, multiple sclerosis; VH, immunoglobulin heavy chain variable region.

J. Clin. Invest.

(c) The American Society for Clinical Investigation, Inc.

$0021-9738 / 91 / 04 / 1266 / 08 \quad \$ 2.00$

Volume 87, April 1991, 1266-1273 dizygotic twins provides strong evidence for a genetically controlled susceptibility to MS $(6,7)$. Despite this information, specific genes which predispose to MS have not been identified. However, an immune process is generally considered to be involved in MS initiation and progression.

Abnormalities of the immune system have been observed in the peripheral blood and CNS of MS patients although there is as yet no formal proof that MS is mediated by either humoral or cellular mechanisms (for reviews see references 8-10). Genetic susceptibility associated with the MHC locus of the human leukocyte antigen (HLA) system has been implicated. An increased frequency of the HLA-A3, B7, DR2 haplotype has been observed in European MS populations (reviewed in references 11-13). However, many sib pairs concordant for MS do not share HLA haplotypes (14).

Many spontaneous models of autoimmune disease invoke the interaction of multiple loci (15). However, there is no spontaneous model of MS. Animal susceptibility to experimental allergic encephalomyelitis (EAE), an autoimmune disease induced in animals by immunization with myelin, is also controlled by more than one locus (16). Analysis of EAE animals indicates that $\mathrm{T}$ cells may have a role in the development of MS (reviewed in references $8,10,17$ ), although the failure to detect $T$ cells reactive to myelin basic protein (MBP) in the peripheral blood of MS patients suggests that EAE could be distinct from MS (18). Recent evidence suggests that a restricted set of the TCR $V \alpha$ and $J \alpha$ gene segments are rearranged in the brains of MS patients (19). Analysis of the distribution of haplotypes of the TCR $\alpha$ and $\beta$ chain loci in MS patients suggests that T cells have a role in MS susceptibility (20-22).

The immunoglobulin heavy chain (IGH) complex may also have a role in MS susceptibility and pathogenesis. Recent evidence suggests that increased levels of CNS autoantibodies are associated with MS disease activity and may be involved in the demyelination process $(23,24)$. The systematic addition of antiwhite matter antibodies to EAE rodents was found not only to accelerate demyelination, but also to participate in the initiation of myelin breakdown (25). While autoantibodies to CNS components may be secondary to the initiation of MS, the production of these autoantibodies could be important in the pathogenesis of MS and in potential antibody-dependent, cellmediated, demyelination. If this is the case, the genes of the IGH complex warrant study in MS patients.

To determine if the IGH complex has a role in MS susceptibility, polymorphisms of both the constant $(\mathrm{CH})$ and the variable $(\mathrm{VH})$ regions should be studied. DNA restriction fragment length polymorphisms have now been characterized for most of the $\mathrm{CH}$ region genes: $\mu, \delta, \gamma 1, \gamma 3, \alpha 1, \psi \gamma, \gamma 2, \gamma 4$, and $\alpha 2$ (26-31). The recent completion of physical maps of the $\mathrm{CH}$ region $(32,33)$ has allowed comparison of the distribution of alleles of $\mathrm{CH}$ polymorphic loci with physical distance. Linkage disequilibrium analysis (27) and linkage analysis (34) of $\mathrm{CH}$ 
region polymorphisms have revealed that a hot spot for recombination lies in the $\sim 70-\mathrm{kb}$ interval between the $\mathrm{C} \delta$ and $\mathrm{C} \gamma 3$ genes. The availability of a large number of DNA polymorphisms in the $\mathrm{CH}$ region and the evidence of a hot spot for recombination within the $\mathrm{CH}$ region, has allowed selection of a set of seven $\mathrm{CH}$ polymorphisms for use in association studies (Gibson et al., manuscript in preparation).

The VH gene segments, coding for the first 95-101 amino acids of the heavy chain peptide, have been subdivided into six families (VH1-VH6) based upon DNA homology (35-39). Extensive polymorphisms of the $\mathrm{VH}$ region have also been found (40-47). We have recently reported a physical map of the VH region (48). This map includes the positions of VH polymorphic loci, and allowed our selection of eight $\mathrm{VH}$ polymorphic loci distributed over $1,000 \mathrm{~kb}$ of the $\mathrm{VH}$ region for use in disease association studies.

Based on the autoimmune reaction apparent in MS, and the HLA and TCR associations, we looked for association between MS and the immunoglobulin $\mathrm{CH}$ and $\mathrm{VH}$ regions. The allelic distributions of 15 DNA polymorphisms mapping to a $1,500-\mathrm{kb}$ region of the IGH locus were determined for MS patients and controls in two consecutive studies. In both MS groups a significant association was found with a VH2 family gene segment. This suggests that the immunoglobulin $\mathrm{VH}$ region contributes to the genetic control of susceptibility to MS.

\section{Methods}

MS patient ascertainment. The characteristics of the MS patient population from which the MS patients analyzed in this report were drawn have been extensively documented $(2,49)$.

Study 1. DNA was extracted from the peripheral blood leukocytes of $32 \mathrm{sib}$ pairs and $2 \mathrm{sib}$ trios concordant for MS (14). These familial MS patients were from the Southwestern Ontario region and of Northern European descent.
Study 2. DNA from 23 sporadic MS patients was examined to determine the distribution of the alleles of the 15 IGH polymorphisms in a second MS group. This MS patient group represents a random sample of the sporadic patients visiting the London Ontario Multiple Sclerosis Clinic. DNA was extracted from peripheral blood leukocytes for analysis.

Control population. Controls used in this study consisted of members of $\alpha_{1}$-antitrypsin deficiency kindreds and 8 controls from other normal families. In this control population, 23 individuals were heterozygous for the $\alpha_{1}$-antitrypsin deficiency allele (the " $Z$ " allele) and 39 were unrelated spouses (not containing the $Z$ allele). 10 additional haplotypes were determined from incomplete pedigrees. $\alpha_{1}$-antitrypsin deficiency is a common metabolic disorder not known to be associated with MS (50).

These controls were suitable for comparison, as they are of similar ethnic background (Caucasians of Northern European descent) and from the same geographical region (Southwestern Ontario) as both of the MS patient groups studied here, an important feature because of ethnic differences in IGH markers. Allele frequencies for this control population for the $\mathrm{CH}$ region polymorphisms $(26,27)$ and the VH region polymorphisms $(42,47$, and Gibson, unpublished results) were previously determined and are shown in Table I. DNA was extracted from peripheral blood leukocytes.

Electrophoretic analysis. $3 \mu \mathrm{g}$ of DNA were digested with 9-12 U of the restriction endonucleases Bgl II, Eco RI, Sac I, Bam HI, and Xba I (Boehringer-Mannheim, Laval, Quebec, and Pharmacia Inc., Baie d'Urfe, Quebec) in manufacturers' recommended buffers overnight at $37^{\circ} \mathrm{C}$. Bgl II-, Eco RI-, and Sac I-digested DNA was electrophoresed in $0.7 \%$ agarose gels containing $0.8 \mu \mathrm{g} / \mathrm{ml}$ ethidium bromide for 1,200 1,600 volt-hours; Xba I-digested DNA was electrophoresed in $0.6 \%$ agarose for 1,400-1,500 Volt-hours; and Bam HI-digested DNA was electrophoresed in $0.35 \%$ agarose for $1,400-1,600$ volt-hours. After being photographed, gels were submerged in $0.25 \mathrm{~N} \mathrm{HCl}$ for $10 \mathrm{~min}(20$ min for Bam HI-digested DNA), briefly rinsed with distilled $\mathrm{H}_{2} \mathrm{O}$, denatured, neutralized, and transferred to Hybond nylon membrane according to the manufacturer's protocol (Amersham Corp., Arlington Heights, IL). Membranes were baked at $80^{\circ} \mathrm{C}$ for $2 \mathrm{~h}$ and cross-linked with ultraviolet light $\left(365 \mathrm{~nm}\right.$, intensity $7,000 \mu \mathrm{W} / \mathrm{cm}^{2}$ at the filter

Table I. Allele Designations and Frequencies of 15 IGH Polymorphisms

\begin{tabular}{|c|c|c|c|c|c|c|}
\hline Region & Gene & Enzyme & Alleles & Frequency & $\mathbf{N}$ & Refereno \\
\hline \multicolumn{7}{|c|}{$k b$} \\
\hline \multirow[t]{8}{*}{ VH } & VH3f-1 & Eco RI & $6.7,0$ & $0.28,0.72$ & 134 & 47 \\
\hline & VH2-2 & $\mathrm{Bgl} \mathrm{II}$ & 12,0 & $0.28,0.72$ & 134 & 41 \\
\hline & VH3f-3 & Eco RI & $4.3,0$ & $0.74,0.26$ & 61 & $*$ \\
\hline & VH2-4 & $\mathrm{Bgl} \mathrm{II}$ & $7.3,7.0$ & $0.06,0.94$ & 134 & 41 \\
\hline & VH3f-4 & Eco RI & $3.5,0$ & $0.13,0.87$ & 134 & 47 \\
\hline & VH3f-2 & Eco RI & $6.0,4.6$ & $0.83,0.17$ & 134 & 47 \\
\hline & VH5-2 & Bgl II & 8,0 & $0.50,0.50$ & 110 & 42 \\
\hline & VH2-5 & Bgl II & $3.4,0$ & $0.45,0.55$ & 134 & 41 \\
\hline \multirow[t]{7}{*}{$\mathrm{CH}$} & $\mu$ & Sac I & $2.7,2.2$ & $0.54,0.46$ & 64 & 30 \\
\hline & $\delta$ & Xba I & 17,13 & $0.68,0.32$ & 148 & 27 \\
\hline & $\alpha 1$ & Sac I & $7.4^{\ddagger}$ & $0.71,0.29$ & 82 & 30 \\
\hline & $\Psi \gamma$ & Bam HI & $10,8.8$ & $0.50,0.50$ & 128 & 26 \\
\hline & $\gamma 2$ & Bam HI & $25,13.5$ & $0.57,0.43$ & 128 & 26 \\
\hline & $\gamma 4$ & Bam HI & $9.4,9.0$ & $0.56,0.44$ & 136 & 26 \\
\hline & $\alpha 2$ & SacI & , 4.8 & $0.09,0.91$ & 58 & 30 \\
\hline
\end{tabular}

\footnotetext{
* Gibson et al., manuscript in preparation. ${ }^{\ddagger}$ The $\mathrm{C} \alpha 1$ 6.8- and 6.9-kb alleles were pooled. ${ }^{5}$ The rare $\mathrm{C} \alpha 2$ 5.5-, 5.3-, and 5.2-kb alleles were pooled. An allele size of 0 indicates that an allelic counterpart to a polymorphic fragment could not be found. Enzyme, the restriction enzyme used to detect the polymorphism. Frequency, The allele frequencies of the polymorphisms in the control population studied here. $N$ Number of control chromosomes typed. Reference, The original description of the polymorphism.
} 
surface) for $1 \mathrm{~min}$. The membranes were prehybridized for $1 \mathrm{~h}$ and hybridized for $18-24 \mathrm{~h}$ at $65^{\circ} \mathrm{C}$ with $0.5-1.0 \times 10^{6} \mathrm{cpm}$ of random primed probe per milliliter of hybridization solution (Pharmacia Inc. random priming kit). Prehybridization and hybridization solutions were as described (51). Membranes were washed for $0.5 \mathrm{~h}$ in $2 \times$ SSC and then for $1 \mathrm{~h}$ in $0.1 \times \mathrm{SSC}, 0.1 \%$ SDS at $52^{\circ} \mathrm{C}$ (for the VH2EB1.2, VHE2.2, $2-\mathrm{V}$, and $24 \mathrm{BRH}$ probes) or $65^{\circ} \mathrm{C}$ (for the VH6B9.3, $\mathrm{S} \mu$, and pCW 101 probes). Autoradiography was performed using DuPont Co., (Wilmington, DE) Lightning Plus intensifying screens over periods of up to a week.

DNA probes. Inserts to be used as probes were: $24 \mathrm{BRH}$, a 2-kb Hind III/Eco RI fragment containing $C \gamma 4$ coding sequences (26); $S \mu$, a 2.2$\mathrm{kb} \mathrm{Sac} \mathrm{I} \mathrm{fragment} \mathrm{derived} \mathrm{from} \mathrm{the} \mathrm{switch} \mathrm{region} \mathrm{of} \mathrm{the} \mathrm{C} \mu$ gene (30); CW101, a 2.7-kb Pst I/Bam HI fragment located 5' to the C $\delta$ gene (27); VH2EB1.2, a 1.2-kb Eco RI/Bam HI fragment containing a VH2 family gene (47); VHE2.2, a 2.2-kb Eco RI fragment (47) which flanks the VH3 gene segment VH26 (52); 2-V, a 221-bp Pst I fragment containing a VH5 gene segment (35); and VH6B9.3, a 9.3-kb Bam HI fragment derived from $\mathrm{C} 17 \mathrm{p} 3$, which contains the VH6 family gene (53). DNA probe and restriction enzyme combinations used to detect polymorphisms, and the reported allele frequencies in the control population are shown in Table I.

Statistical analysis. The allele frequencies of the IGH polymorphic loci in the MS patient groups were compared with those of the control population by $\chi^{2}$ analysis. To avoid false positives due to the large number of comparisons computed, only $\chi^{2}$ values with probabilities of less than 0.01 were considered to be significant. Dosage of the VH insertion/deletion polymorphisms was determined by comparison of fragment hybridization intensities with intensities of constant bands within the same lane. Relative risk $(x)$ was calculated using Woolf's formula: $x=p d(1-p c) /(1-p d) p c(54)$, where $p d$ and $p c$ are the frequencies of the phenotype in patient and control individuals, respectively.

\section{Results}

Study 1 . 15 polymorphic loci mapping to a $1,500-\mathrm{kb}$ region of the IGH locus were characterized in $\mathbf{3 2}$ sib pairs and 2 sib trios concordant for familial MS. For each polymorphism, one sib was randomly selected from each pair or trio and the genotype of that individual was used for data analysis. The allele frequencies for the familial MS group were then compared with the control population from Southern Ontario. The results of this analysis for the eight VH polymorphisms are shown in Table II; the results of the analysis of the seven $\mathrm{CH}$ polymorphisms are shown in Table III. No association was detected between the $\mathrm{CH}$ polymorphisms and MS. However, the analysis of VH polymorphisms revealed a significant association between MS and a VH2 family gene segment, VH2-5 $\left(\chi^{2}=8.16\right.$, $P<0.005)$. The frequency of the 3.4-kb insertion allele of this insertion/deletion polymorphism was significantly elevated in MS patients (corresponding to a relative risk of 1.99). The

Table II. VH Region Polymorphisms and Multiple Sclerosis

\begin{tabular}{|c|c|c|c|c|c|c|c|}
\hline \multirow[b]{2}{*}{ Gene } & \multirow[b]{2}{*}{ Genotype* } & \multicolumn{3}{|c|}{ Study 1} & \multicolumn{3}{|c|}{ Study 2} \\
\hline & & Familial MS & Expected & $x^{2}$ & Sporadic MS & Expected & $x^{2}$ \\
\hline & $6.7 / 6.7$ & 4 & 2.7 & & 2 & 1.8 & \\
\hline \multirow[t]{3}{*}{ VH3f-1 } & $6.7 / 0$ & 12 & 13.7 & 0.85 & 13 & 9.3 & 2.77 \\
\hline & $0 / 0$ & 18 & 17.6 & & 8 & 11.9 & \\
\hline & $12 / 12$ & 4 & 2.7 & & 2 & 1.8 & \\
\hline \multirow[t]{3}{*}{ VH2-2 } & $12 / 0$ & 11 & 13.7 & 1.27 & 13 & 9.3 & 2.77 \\
\hline & $0 / 0$ & 19 & 17.6 & & 8 & 11.9 & \\
\hline & $4.3 / 4.3$ & 23 & 18.6 & & 15 & 12.6 & \\
\hline \multirow[t]{3}{*}{ VH3f-3 } & $4.3 / 0$ & 9 & 13.1 & 2.36 & 8 & 8.9 & 2.05 \\
\hline & $0 / 0$ & 2 & 2.3 & & 0 & 1.5 & \\
\hline & $7.0 / 7.0$ & 26 & 28.3 & & 18 & 19.4 & \\
\hline \multirow[t]{3}{*}{ VH2-4 } & $7.0 / 7.3$ & 6 & 3.6 & 1.94 & 3 & 2.5 & $10.79^{8}$ \\
\hline & $7.3 / 7.3$ & 0 & 0.1 & & 1 & 0.1 & \\
\hline & $0 / 0$ & 30 & 25.7 & & 19 & 17.4 & \\
\hline \multirow[t]{3}{*}{ VH $3 f-4$} & $3.5 / 0$ & 4 & 7.7 & 3.05 & 4 & 5.2 & 0.82 \\
\hline & $3.5 / 3.5$ & 0 & 0.6 & & 0 & 0.4 & \\
\hline & $6.0 / 6.0$ & 22 & 23.4 & & 16 & 15.8 & \\
\hline \multirow[t]{3}{*}{ VH3f-2 } & $6.0 / 4.6$ & 12 & 9.6 & 1.68 & 7 & 6.5 & 0.74 \\
\hline & $4.6 / 4.6$ & 0 & 1.0 & & 0 & 0.7 & \\
\hline & $8 / 8$ & 8 & 8.5 & & 7 & 5.5 & \\
\hline \multirow[t]{3}{*}{ VH5-2 } & $8 / 0$ & 12 & 17.0 & 5.06 & 6 & 11.0 & 4.91 \\
\hline & $0 / 0$ & 14 & 8.5 & & 9 & 5.5 & \\
\hline & $3.4 / 3.4$ & 13 & 6.9 & & 10 & 4.6 & \\
\hline \multirow[t]{2}{*}{ VH2-5 } & $3.4 / 0$ & 16 & 16.8 & $8.16^{\ddagger}$ & 6 & 11.4 & $8.90^{\ddagger}$ \\
\hline & $0 / 0$ & 5 & 10.3 & & 7 & 7.0 & \\
\hline
\end{tabular}

* Genotype allele designations are in kb. $n=34$ for study $1 ; n=23$ for study 2, except for the VH2-4 and VH5-2 polymorphisms for which $n$ $=22 .{ }^{\ddagger} \chi^{2}$ values significant at $P<0.005 .{ }^{8} \chi^{2}$ value is high due to the detection of a single rare event and probably does not indicate a significant association. 


\begin{tabular}{|c|c|c|c|c|c|c|c|}
\hline \multirow[b]{2}{*}{ Gene } & \multirow[b]{2}{*}{ Genotype* } & \multicolumn{3}{|c|}{ Study 1} & \multicolumn{3}{|c|}{ Study 2} \\
\hline & & Familial MS & Expected & $x^{2}$ & Sporadic MS & Expected & $x^{2}$ \\
\hline \multirow{3}{*}{$\mu$} & $2.7 / 2.7$ & 10 & 9.9 & & 5 & 6.7 & \\
\hline & $2.7 / 2.2$ & 18 & 16.9 & 0.27 & 9 & 11.4 & 4.37 \\
\hline & $2.2 / 2.2$ & 6 & 7.2 & & 9 & 4.9 & \\
\hline \multirow{3}{*}{$\delta$} & $17 / 17$ & 21 & 15.7 & & 8 & 10.2 & \\
\hline & $17 / 13$ & 12 & 14.8 & 4.09 & 10 & 9.6 & 1.96 \\
\hline & $13 / 13$ & 1 & 3.5 & & 4 & 2.2 & \\
\hline \multirow{3}{*}{$\alpha 1$} & $7.4 / 7.4$ & 17 & 17.1 & & 12 & 11.6 & \\
\hline & $7.4 /^{ \pm}$ & 15 & 14.0 & 0.35 & 8 & 9.5 & 0.88 \\
\hline & 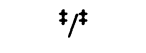 & 2 & 2.9 & & 3 & 1.9 & \\
\hline \multirow{3}{*}{$\psi \gamma$} & $10 / 10$ & 9 & 8.5 & & 7 & 5.5 & \\
\hline & $10 / 8.8$ & 15 & 17.0 & 0.53 & 10 & 11.0 & 0.55 \\
\hline & $8.8 / 8.8$ & 10 & 8.5 & & 5 & 5.5 & \\
\hline \multirow{3}{*}{$\gamma 2$} & $25 / 25$ & 9 & 11.0 & & 7 & 7.1 & \\
\hline & $25 / 13.5$ & 15 & 16.7 & 2.98 & 9 & 10.8 & 1.18 \\
\hline & $13.5 / 13.5$ & 10 & 6.3 & & 6 & 4.1 & \\
\hline \multirow{3}{*}{$\gamma 4$} & $9.4 / 9.4$ & 11 & 10.7 & & 4 & 6.9 & \\
\hline & $9.4 / 9.0$ & 15 & 16.7 & 0.22 & 11 & 10.8 & 2.85 \\
\hline & $9.0 / 9.0$ & 7 & 6.6 & & 7 & 4.2 & \\
\hline \multirow{3}{*}{$\alpha 2$} & 4.8 & 33 & 28.2 & & 19 & 19.0 & \\
\hline & $8 / 4.8$ & 1 & 5.6 & 4.90 & 3 & 3.8 & 3.37 \\
\hline & $8 / s$ & 0 & 0.3 & & 1 & 0.2 & \\
\hline
\end{tabular}

* Genotype allele designations are in kb. $n=34$ for study $1 ; n=23$ for study 2 , except for the $\mathrm{C} \delta, \mathrm{C} \gamma 2, \mathrm{C} \psi \gamma$, and $\mathrm{C} \gamma 4$ polymorphisms for which $n=22 .{ }^{\ddagger}$ The $\mathrm{C} \alpha 16.8$ - and $6.9-\mathrm{kb}$ alleles were pooled. ${ }^{5} \mathrm{The}$ rare $\mathrm{C} \alpha 25.2-, 5.3-$, and $5.5-\mathrm{kb}$ alleles were pooled.

VH2-5 polymorphism is in Hardy-Weinberg equilibrium in the MS group (data not shown). An autoradiograph of DNA of MS patients digested with $\mathrm{Bgl}$ II and hybridized with the VH2 probe is shown in Fig. 1.

In Table IV, the frequencies of the classes of sib pairs of the VH2-5 polymorphism observed in the familial MS sibships were compared with those found in the controls. This test uses the entire familial MS sib pair data set, rather than only half of it, as was previously done in Tables II and III. Two sibs were randomly selected from each of the two trio MS sibships for this analysis. The frequencies of the classes of sib pairs of the VH2-5 polymorphism MS population were found to differ significantly from the frequencies of the control population due to the elevated frequency of the 3.4-kb allele of $\mathrm{VH} 2-5$ in the MS patient group $\left(\chi^{2}=15.32, P<0.001\right)$.

The MS patients were also investigated for possible alterations of the nonpolymorphic VH6 locus. Fig. 2 shows the physical localization of VH6, the most $\mathrm{CH}$-proximal $\mathrm{VH}$ gene segment. In Bgl II-digested DNA the VH6B9.3 probe hybridizes to a $6.6-\mathrm{kb}$ fragment containing the single VH6 gene segment and to a 20-kb fragment that is $5^{\prime}$ of the VH6 locus (48). No differences of VH6 Southern blot hybridization patterns or intensities between the familial MS group and controls were discovered.

Study 2. A second, independent, study was carried out to determine if the observation of a significant association between VH2-5 and MS could be reproduced. The allele frequencies of the $15 \mathrm{IGH}$ polymorphisms were determined in $23 \mathrm{spo-}$ radic MS patients. The results for the analysis of the $8 \mathrm{VH}$ polymorphisms are shown in Table II; the results of this analysis for the $7 \mathrm{CH}$ polymorphisms are shown in Table III. A significant elevation of the frequency of the 3.4-kb allele of VH2-5 was again observed $\left(\chi^{2}=8.90, P<0.005\right)$, as in study 1 (relative risk $=1.62$ ). No significant association between the other IGH polymorphisms and MS was observed. No alterations involving the nonpolymorphic VH6 locus in the sporadic MS group were identified.

We compared the allele frequencies of the VH2-5 polymorphism in controls, with and without the $\alpha_{1}$-antitrypsin Z deficiency allele, since most of our controls were from families with $\alpha_{1}$-antitrypsin deficiency. No association was found between the VH2-5 polymorphism and the $\alpha_{1}$-antitrypsin $\mathrm{Z}$ allele in our control population $\left(\chi^{2}=0.35\right)$.

The calculated $\chi^{2}$ values of the 15 IGH polymorphic loci studied in the 2 MS patient populations and the physical locations of these polymorphic loci within the IGH complex are shown in Fig. 2.

\section{Discussion}

Roles for both immune dysfunction and viral agents have been proposed for MS initiation and progression (reviewed in reference 9). In order to explore the possibility of IGH locus involvement in susceptibility to MS, we examined the distributions of the alleles of $15 \mathrm{IGH}$ polymorphisms, 7 in the $\mathrm{CH}$ region and 8 in the $\mathrm{VH}$ region, in both familial and sporadic MS patients. These familial and nonfamilial MS groups have been examined for clinical and demographic features and were found not 


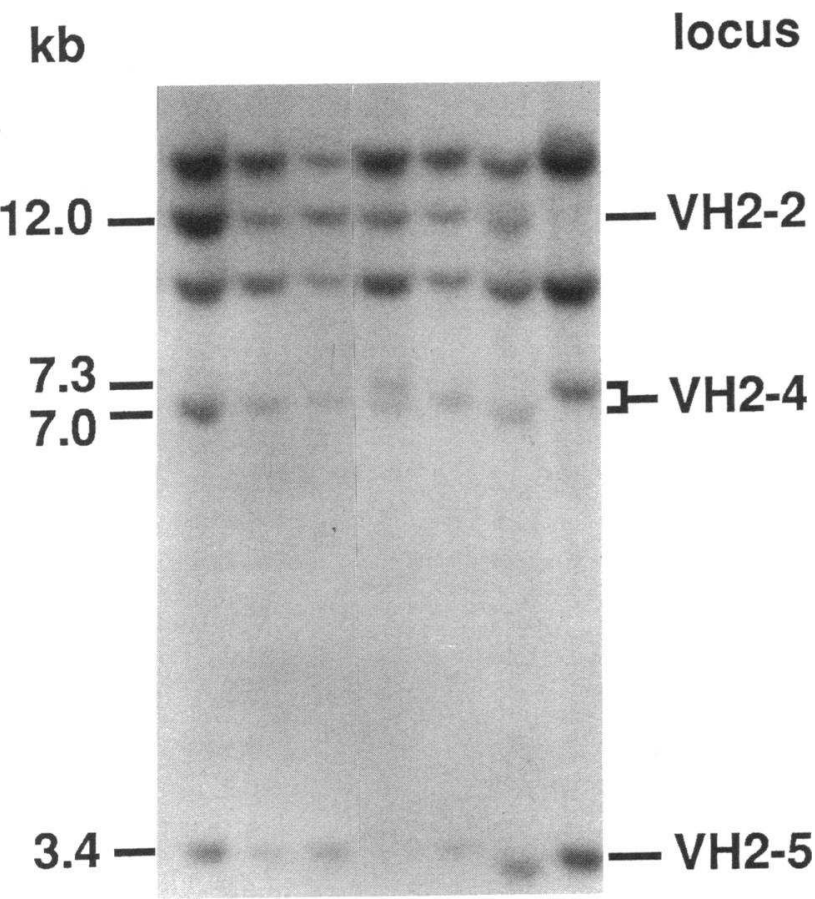

Figure 1. DNA from patients with multiple sclerosis digested with $\mathrm{Bgl}$ II and hybridized with a VH2 family probe. Polymorphic VH2 gene segments are identified to the right, fragment sizes are indicated to the left.

to differ (56). In both of these MS groups, we found a significant association with the VH polymorphic locus VH2-5. The general low levels of linkage disequilibrium between the $\mathrm{VH}$ polymorphic loci in the normal population $(47,55)$ precluded the identification of $\mathrm{VH}$ region haplotypes in the MS patients. Efforts are now underway to characterize the parents or offspring of MS patients to investigate potential differences in $\mathrm{VH}$ haplotype frequencies in MS patients.

We have selected a control population particularly well matched ethnically and geographically to our MS patients, because of well established ethnic differences for immunoglobulin markers. While we selected controls mostly from families with the $\alpha_{1}$-antitrypsin deficiency allele $(\mathrm{Z})$, more than half were unrelated spouses. There is no association between the $\alpha_{1}$-antitrypsin Z allele and MS (50). Furthermore, in our study, we have shown no difference between the VH2-5 allele frequencies in $\alpha_{1}$-antitrypsin PI type MZ (deficiency heterozygotes) and $\alpha_{1}$-antitrypsin non- $Z$ individuals. Our control group is therefore suitable for disease association studies involving MS and VH2-5.

Previous studies investigating the role of the immunoglobulin heavy chain gene cluster in MS susceptibility have used only $\mathrm{CH}$ region polymorphisms. The results of these studies have been inconsistent. Several studies reported an elevation of the IgG marker $\mathrm{Gm}^{1,17 ; 21}$ haplotype in MS patients (57-59). However, Bulman et al. (60) found no association and Haile et al. (61) found no linkage between Gm markers and MS. Gaiser et al. (28) reported an association between a DNA polymorphism of IgG3 and MS, but found no association between IgG1 and MS. Furthermore, the IgG3 association was with the opposite allele of IgG3 reported elevated in MS patients in the previous studies (57-59).

The different results found in the studies of association of the $\mathrm{CH}$ region of the IGH complex to MS susceptibility could be due to several factors. Geographical stratification and local variation in ethnic composition has been suggested as a possible explanation, as well as the possibility that different environmental factors may involve different MS susceptibility loci. However, as different results in association studies between MS and the $\mathrm{CH}$ region have been reported for MS patients from the same geographical regions $(28,57,61,62)$, other explanations including incompatible control groups, may be more probable.

Our study, using seven $\mathrm{CH}$ region polymorphisms and eight $\mathrm{VH}$ polymorphisms, found no association between the $\mathrm{CH}$ region and MS patients, consistent with the earlier report in the Canadian MS population of no association with the $\mathrm{Gm}$ allotypes (60). The recent identification of a hot spot for recombination between the $C \delta$ and $C \gamma 3$ genes $(27,34)$ suggests that association between MS and the $\mathrm{VH}$ region could not be identified using IgG polymorphisms alone. The studies reported here are the first to use VH polymorphic loci in association studies with MS. We found that both familial MS and sporadic MS patient groups had a significantly increased frequency of the insertion allele of the VH2 polymorphic gene segment VH2-5.

VH2-5 has been mapped to a region between 180 and 360 $\mathrm{kb}$ from the $\mathrm{CH}$ region (48). The $\mathrm{VH} 5$ polymorphic locus,

Table IV. Frequencies of the VH2-5 Polymorphism for MS Sib Pairs

\begin{tabular}{|c|c|c|c|c|c|}
\hline \multirow[b]{2}{*}{ Sib pair classes } & \multirow[b]{2}{*}{ Formula } & \multicolumn{2}{|c|}{ Expected } & \multirow{2}{*}{$\begin{array}{l}\text { Observed } \\
\text { number }\end{array}$} & \multirow[b]{2}{*}{$x^{2}$} \\
\hline & & Frequency & Number & & \\
\hline$(3.4,3.4) ;(3.4,3.4)$ & $\mathbf{p}^{2}\left(1-3 / 4 \mathbf{q}^{2}-\mathbf{p q}\right)$ & 0.106 & 3.60 & 6 & 1.60 \\
\hline$(3.4,3.4) ;(3.4,0)$ & $p^{2}\left(1-p^{2}\right)$ & 0.161 & 5.47 & 10 & 3.73 \\
\hline$(3.4,3.4) ;(0,0)$ & $1 / 2\left(p^{2} q^{2}\right)$ & 0.031 & 1.05 & 3 & 3.62 \\
\hline$(3.4,0) ;(3.4,0)$ & $\mathrm{pq}(1+\mathrm{pq})$ & 0.309 & 10.51 & 6 & 1.94 \\
\hline$(3.4,0) ;(0,0)$ & $q^{2}\left(1-p^{2}\right)$ & 0.211 & 7.17 & 8 & 0.10 \\
\hline$(0,0) ;(0,0)$ & $q^{2}\left(1-3 / 4 p^{2}-p q\right)$ & 0.182 & 6.15 & 1 & 4.31 \\
\hline Total & 1 & 1 & 34 & 34 & $15.32^{*}$ \\
\hline
\end{tabular}

$(3.4,3.4),(3.4,0)$, and $(0,0)$ represent MS patients homozygous for the 3.4-kb allele of VH2-5, heterozygous, and homozygous for the 0 allele of the VH2-5 polymorphism, respectively. Expected values were obtained using the VH2-5 allele frequencies found in the control population described in the text. Two sibs were randomly selected from each of the two MS trio sibships, for this analysis. ${ }^{*}$ This $\chi^{2}$ value is significant at $P$ $<0.001$. 


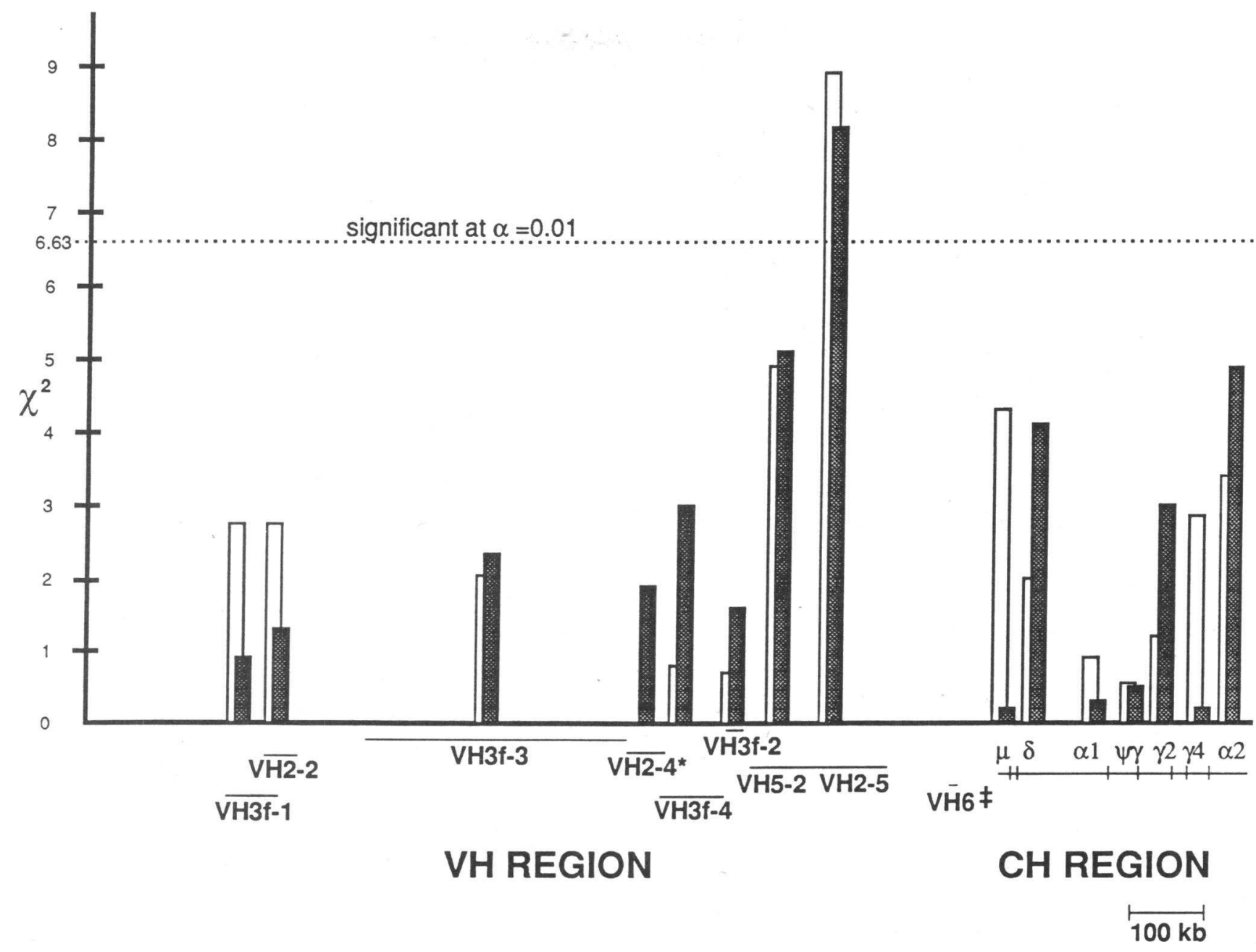

Figure 2. The physical locations of 15 immunoglobulin polymorphic loci and their associated $\chi^{2}$ values in familial and in sporadic multiple sclerosis patients. $\chi^{2}$ values are taken from Tables II and III; VH polymorphic loci positions are those reported in reference 48 . The line above each VH polymorphic locus indicates the position of this polymorphism within the IGH complex. The positions of the $\mathrm{CH}$ polymorphic loci are taken from reference 32. The significance level of $\alpha=0.01$ is indicated $\left(\chi^{2}=6.63\right)$. ${ }^{*}$ The $\chi^{2}$ value of the VH2-4 polymorphism in the sporadic MS ( $\square$ ) patient group is not shown as it is high due to the detection of a single rare event, and probably does not indicate a significant association (Table II). ${ }^{\ddagger}$ No differences between the familial MS ( $\square$ ) patients and the control population were observed involving the non-polymorphic VH6 locus.

VH5-2, also maps to this interval (Fig. 2) and shows some evidence of association with MS in both familial and sporadic MS groups (Table II). However, as the alleles of VH2-5 and VH5-2 are in linkage disequilibrium in the control population $\left(r=0.70 ; \chi^{2}=53.53, P<0.001\right)(55)$, the slight association of MS with VH5-2 is probably the result of the real association of MS with the VH2-5 gene segment. The VH2-5 and VH5-2 polymorphisms are in linkage equilibrium with all other $\mathrm{VH}$ and $\mathrm{CH}$ polymorphisms studied here $(47,55$ and Walter, unpublished results).

The association between MS and the VH2-5 gene segment could have several explanations. The VH2-5 gene segment could encode the variable region of an antibody with antigen specificity to a component of the myelin sheath. The predisposition of particular VH gene segment products toward binding self antigens has been demonstrated in other autoimmune disorders, most notably in $\operatorname{SLE}(63,64)$ and in rheumatic disease $(65,66)$. Alternatively, VH2-5 could be indirectly involved in MS susceptibility, perhaps mapping near a VH gene segment with MS-associated autoimmune specificity. With this in mind, it is intriguing that a VH3 family gene segment (PopVH) has recently been cloned that has anti-myelin and anti-DNA activities in a patient with peripheral neuropathy (67). PopVH is $96 \%$ homologous to the VH3 gene segment VH26 (52). VH26 has been shown to encode the heavy chain variable region of antibodies with anti-DNA activity $(63,66)$. The sequence differences between PopVH and VH26 may be the result of somatic mutation, genetic variation of the same VH gene segment, or could imply that PopVH is encoded by a different germline $\mathrm{VH} 3$ gene segment that is very similar to VH26. As the VH26 gene segment has been physically localized close to VH2-5 (48), the germline PopVH gene segment may map to the same region as VH2-5, if similar VH gene segments are physically clustered, or if PopVH is an allele of the VH26 gene segment. We speculate that the association we have observed between MS and VH2-5 could be the result of an association between MS and an anti-myelin $\mathrm{VH}$ gene segment which maps close to VH2-5. VH6, VH26, and VH2-5 have been associated with an autoimmune response (63-66; and this paper). All of these VH gene segments are physically located in 
the $\mathrm{CH}$-proximal $\mathrm{VH}$ region (48). Others $(38,64,68-70)$ have suggested that the $\mathrm{VH}$ gene segments mapping to this region are preferentially used in murine and human fetal ontogeny. It has been suggested that the cells expressing Ig receptors encoded by $3^{\prime} \mathrm{VH}$ gene families could be selected by antigen and/ or $T$ cells early in ontogeny and in autoimmune diseases, as the VH from these families are preferentially used by autoreactive clones (71). It will be interesting to discover whether the $\mathrm{CH}$ proximal VH gene segments generally encode autoantibodies, and if this autoantibody bias is associated with fetal expression.

The current evidence suggests that multiple sclerosis occurs in genetically susceptible individuals who are exposed to as yet unidentified environmental triggers. The data from this report suggest that a locus involved in genetic susceptibility to MS, in addition to loci near the HLA and TCR complexes, might be found in or near the immunoglobulin $\mathrm{CH}$ proximal $\mathrm{VH}$ region. These susceptibility loci may act in concert with each other in an epistatic manner, and with other, as yet unidentified loci, to provide the genetic background necessary for the development of multiple sclerosis.

\section{Acknowledgments}

We thank Holly Armstrong for expert technical assistance and Mary Grace Brubacher, Dennis Bulman, and Kirsten Krismer for thoughtful review of the manuscript. This study was supported by grants from the National Multiple Sclerosis Society, the Multiple Sclerosis Society of Canada, and by a summer studentship to Dr. Gibson partially funded by the Lunenfeld Foundation.

\section{References}

1. Silberberg, D. H. 1988. The demyelinating diseases. In Cecil Textbook of Medicine. J. B. Wyngaarden and L. H. Smith Jr., editors. W. B. Saunders Co. Philadelphia. 2211-2217.

2. Hader, W. J., M. Elliott, and G. C. Ebers. 1988. Epidemiology of multiple sclerosis in London and Middlesex County, Ontario, Canada. Neurology. 38:617-621.

3. Ebers, E. C. 1986. Multiple sclerosis and other demyelinating diseases. In Diseases of the Nervous System. A. Asburry, G. McKhann, and I. McDonald, editors. W. B. Saunders Co., Philadelphia. 1638-1642.

4. Sadovnick, A. D., and P. M. J. Macleod. 1981. The familial nature of multiple sclerosis: empiric recurrence risks for first, second, and third degree relatives of patients. Neurology. 31:1039-1041.

5. Ebers, G. C. 1983. Genetic factors in multiple sclerosis. Neurologic Clinics of North America. 1:645-654.

6. Ebers, G. C., D. E. Bulman, A. D. Sadovnick, D. W. Paty, S. Warren, W. Hader, T. J. Murray, T. P. Seland, P. Duquette, T. Grey, R. Nelson, M. Nicolle and D. Brunet. 1986. A population-based study of multiple sclerosis in twins. $N$ Engl. J. Med. 315:1638-1642.

7. Kinnunin, E., M. Koskenvuo, J. Kapprio, and K. Aho. 1986. Multiple sclerosis in a nationwide series of twins. Neurology. 37:1627-1629.

8. Calder, V., S. Owen, C. Watson, M. Feldmann, and A. Davison. 1989. MS a localized immune disease of the central nervous system. Immunol. Today. 10:99-103.

9. Waksman, B. H. 1988. Autoimmunity in demyelinating disease. Ann. NY Acad. Sci. 540:13-25.

10. Hafler, D. A., and H. L. Weiner. 1989. MS: a CNS and autoimmune disease. Immunol. Today. 10:104-107.

11. Antel, J. P., and B. G. W. Arnason. 1987. Demyelinating diseases. In Harrison's Principles of Internal Medicine. E. Braunwald, K. J. Isselbacher, R. G. Petersdorf, J. D. Wilson, J. M. Martin, and A. S. Fauci, editors. McGraw-Hil Book Co., New York. 1995-2000.

12. Haile, R. W., S. E. Hodge, and L. Iselius. 1983. Genetic susceptibility to multiple sclerosis: a review. Int. J. Epidemiol. 12:8-16.

13. McDonald, W. I. 1984. Multiple sclerosis: epidemiology and HLA associations. Ann. NY Acad. Sci. 436:109-117.

14. Ebers, G. C., D. W. Paty, C. Stiller, R. Nelson, and T. Seland. 1982. HLA typing in MS sibling pairs. Lancet. 88-90.

15. Smith, H. D., and A. D. Steinberg. 1983. Autoimmunity - a perspective. Annu. Rev. Immunol. 1:175-210.
16. Linthicum, D. S., and J. A. Frelinger. 1982. Acute autoimmune encephalomyelitis in mice. J. Exp. Med. 155:31-40.

17. Kumar, V., D. H. Kono, J. L. Urban, and L. Hood. 1989. The T-cell receptor repertoire and autoimmune disease. Annu. Rev. Immunol. 7:657-682.

18. Hafler, D. A., D. S. Benjamin, J. Burks, and H. L. Weiner. 1987. Myelin basic protein and proteolipid protein reactivity of brain- and cerebrospinal fluidderived $\mathrm{T}$ cell clones in multiple sclerosis and postinfectious encephalomyelitis. $J$. Immunol. 139:68-72

19. Oksenberg, J. R., S. Stuart, A. B. Begovich, R. B. Bell, H. A. Erlich, L. Steinman, and C. C. A. Bernard. 1990. Limited heterogeneity of rearranged T-cell receptor $\mathrm{V} \alpha$ transcripts in brains of multiple sclerosis patients. Nature (Lond.). 345:344-346.

20. Beall, S. S., P. Concannon, P. Charmley, H. F. McFarland, R. A. Gatti, L. E. Hood, D. E. McFarlin, and W. E. Biddison. 1989. The germline of T cell receptor $\beta$-chain genes in patients with chronic progressive multiple sclerosis. $J$. Neuroimmunol. 21:59-66.

21. Oksenberg, J. R., M. Sherritt, A. B. Begovich, H. A. Erlich, C. C. Berard, L. L. Cavalli-Sforza, and L. Steinman. 1989. T-cell receptor $\mathrm{V} \alpha$ and $\mathrm{C} \alpha$ alleles associated with multiple sclerosis and myasthenia gravis. Proc. Natl. Acad. Sci. USA. 86:988-992.

22. Seboun, E., M. A. Robinson, T. H. Doolittle, T. A. Ciulla, T. J. Kindt, and S. L. Hauser. 1989. A susceptibility locus for multiple sclerosis is linked to the $T$ cell receptor $\beta$ chain complex. Cell. 57:1095-1100.

23. Olsson, T., S. Baig, B. Hojeberg, and H. Link. 1990. Antimyelin basic protein and antimyelin antibody-producing cells in multiple sclerosis. Ann. Neurol. 27:132-136.

24. Warren, K. G., and I. Catz. 1985. Diagnostic value of cerebrospinal fluid anti-myelin basic protein in patients with multiple sclerosis. Ann. Neurol. 20:20 25.

25. Schluesener, H. J., R. A. Sobel, C. Linington, and H. L. Weiner. 1987. A monoclonal antibody against a myelin oligodendrocyte glycoprotein induces relapses and demylenation in a central nervous system autoimmune disease. $J$. Immunol. 139:4016-4021.

26. Bech-Hansen, N. T., P. S. Linsley, and D. W. Cox. 1983. Restriction fragment length polymorphisms associated with immunoglobulin $\mathrm{C} \gamma$ genes reveal linkage disequilibrium and genomic organization. Proc. Natl. Acad. Sci. USA. 80:6952-6956.

27. Benger, J. C., and D. W. Cox. 1989. Polymorphisms of the immunoglobulin heavy-chain delta gene and association with other constant-region genes. $\mathrm{Am}$ J. Hum. Genet. 45:606-614.

28. Gaiser, C. N., M. J. Johnson, G. de Lange, L. Rassenti, L. L. CavalliSforza, and L. Steinman. 1987. Susceptibility to multiple sclerosis associated with an immunoglobulin gamma 3 restriction length polymorphism. J. Clin. Invest. 79:309-313.

29. Ghanem, N., M. P. Lefranc, and G. Lefranc. 1988. Definition of the RFLP alleles in the human immunoglobulin IGHG gene locus. Eur. J. Immunol. 18:1059-1065.

30. Migone, N., J. Feder, H. Cann, B. van West, J. Hwang, N. Takahashi, T. Honjo, A. Piazza, and L. L. Cavalli-Sforza. 1983. Multiple DNA fragment polymorphisms associated with immunoglobulin $\mu$ chain switch-like regions in man. Proc. Natl. Acad. Sci. USA. 80:467-471.

31. Bottaro, A., R. Gallina, M. DeMarchi, and A. O. Carbonara. 1989. Genetic analysis of new restriction fragment length polymorphisms (RFLP) in the human IgH constant region locus. Eur. J. Immunol. 19:2151-2157.

32. Hofker, M. H., M. A. Walter, and D. W. Cox. 1989. Complete physical map of the human immunoglobulin heavy chain constant region gene complex. Proc. Natl. Acad. Sci. USA. 86:5567-5571.

33. Bottaro, A., M. de Marchi, N. Migoni, and A. O. Carbonara. 1989. Pulsed field gel analysis of human immunoglobulin heavy-chain constant region gene deletions reveals the extent of unmapped regions within the locus. Genomics. 4:505-508.

34. Benger, J. C., I. Teshima, M. A. Walter, M. G. Brubacher, G. H. Daouk, and D. W. Cox. 1990. Localization and genetic linkage of the human immunoglobulin heavy chain genes and the creatine kinase brain (CKBB) gene: identification of a hot spot for recombination. Genomics. In press.

35. Berman, J. E., S. J. Mellis, R. Pollock, C. L. Smith, H. Suh, B. Heinke, C. Kowal, U. Surti, L. Chess, C. R. Cantor, and F. W. Alt. 1988. Content and organization of the human Ig VH locus: definition of three new VH families and linkage to the Ig CH locus. EMBO (Eur. Mol. Biol. Organ.) J. 7:727-738.

36. Kabat, E. A., T. T. Wu, M. Reid-Miller, H. M. Perry, and K. Gottesman. 1987. Sequences of Proteins of Immunological Interest. 4th ed. U.S. Department of Health and Human Services, Washington, DC. 804 pp.

37. Lee, K. H., F. Matsuda, T. Kinashi, M. Kodaira, and T. Honjo. 1987. A novel family of variable region genes of the human immunoglobulin heavy chain. J. Mol. Biol. 195:761-768.

38. Schroeder, H. W., Jr., J. L. Hillson, and R. M. Perlmutter. 1987. Early restriction of the human antibody repertoire. Science (Wash. DC). 238:791-793.

39. Shen, A., C. Humphries, P. W. Tucker, and F. R. Blattner. 1987. Human heavy-chain variable region gene family nonrandomly rearranged in familial chronic lymphocytic leukemia. Proc. Natl. Acad. Sci. USA. 84:8563-8567. 
40. Chen, P. P., K. A Siminovitch, N.J. Olsen, R. A Erger, and D. A Carson. 1989. A highly informative probe for two polymorphic VH gene regions that contain one or more autoantibody-associated VH genes. J. Clin. Invest. 84:706710 .

41. Johnson, M. J., A. M. Natali, H. M. Cann, T. Honjo, and L. L. CavalliSforza. 1984. Polymorphisms of a human heavy chain gene show linkage with constant heavy chain genes. Proc. Natl. Acad. Sci. USA. 81:7840-7844.

42. Sam, M., M. A. Walter, and D. W. Cox. 1988. Rsa I polymorphism of a human immunoglobulin VH5 subclass locus. Nucleic Acids Res. 16:8748.

43. Souroujon, M. C., D. B. Rubinstein, R. S. Schwartz, and K. J. Barrett. 1989. Polymorphisms in human $H$ chain region genes from the $V_{H} I I I$ gene family. J. Immunol. 143:706-711.

44. Turnbull, I. F., O. Bernard, K. S. Sriprakash, and J. D. Mathews. 1987 Human immunoglobulin variable region genes: a new VH sequence used to detect polymorphisms. Immunogenetics. 25:184-192.

45. van Dijk, K. W., H. W. J. Schroeder, R. M. Perlmutter, and E. C. B. Milner. 1989. Heterogeneity in the human IG VH locus. J. Immunol. 142:25472553.

46. Walter, M. A., P. S. Linsley, and D. W. Cox. 1987. Apa I polymorphism of a human immunoglobulin VH3 subclass locus. Nucleic Acids Res. 15:4697.

47. Walter, M. A., and D. W. Cox. 1988. Analysis of genetic variation reveals human immunoglobulin VH-region gene organization. Am. J. Hum. Genet. 42:446-451.

48. Walter, M. A., U. Surti, M. H. Hofker, and D. W. Cox. 1990. The physical organization of the human immunoglobulin heavy chain gene complex. EMBO (Eur. Mol. Biol. Organ.) J. 9:3303-3313.

49. Weinshenker, B. G., B. Bass, G. P. A. Rice, J. Noseworhty, W. Carriere, J. Baskerville, and G. C. Ebers. 1989. The natural history of multiple sclerosis: a geographically based study: I. Clinical course and disability. Brain. 112:133-146.

50. Francis, D. A., P. T. Klouda, D. M. Brazier, J. R. Batchelor, W. McDonald, and J. E. C. Hern. 1988. Alpha-1-antitrypsin (Pi) types in multiple sclerosis and lack of interaction with immunoglobulin $(\mathrm{Gm})$ markers. J. Immunogenet. (OXF.). 15:251-255

51. Church, G. M., and W. Gilbert. 1984. Genomic sequencing. Proc. Natl. Acad. Sci. USA. 81:1991-1995.

52. Matthyssens, G., and T. H. Rabbitts. 1980. Structure and multiplicity of genes for the human immunoglobulin heavy chain variable region. Proc. Natl. Acad. Sci. USA. 77:6951-6565.

53. Schroeder, H. W., Jr., M. A. Walter, M. H. Hofker, A. Ebens, K. W. van Dijk, L. C. Liao, D. W. Cox, E. C. B. Milner, and R. M. Perlmutter. 1988. Physical linkage of a human immunoglobulin heavy chain variable region gene segment to diversity and joining region elements. Proc. Natl. Acad. Sci. USA. 85:8196-8200.

54. Woolf, B. 1955. On estimating the relation between blood group and disease. Ann. Hum. Genet. 19:251-253.

55. Walter, M. A., M. Sam, J. C. Benger, and D. W. Cox. 1989. Linkage disequilibrium in the human immunoglobulin heavy chain region. Genome. 30 S:202a. (Abstr.)

56. Weinshenker, B. G., D. Bulman, W. Carriere, J. Baskerville, and G. C. Ebers. 1990. A comparison of sporadic and familial multiple sclerosis. Neurology. 40:1354-1358.
57. Pandey, J. P., J.-M. Goust, J.-P. Salier, and H. H. Fudenberg. 1981 Immunoglobulin $\mathrm{G}$ heavy chain $(\mathrm{Gm})$ allotypes in multiple sclerosis. J. Clin. Invest. 67:1797-1800.

58. Propert, D. N., C. C. A. Bernard, and M. J. Simons. 1982. Gm allotypes and multiple sclerosis. J. Immunol. 9:359-361.

59. Sandberg-Wollheim, M., L. G. Baird, M. S. Schanfield, M. H. Knoppers, K. Youker, and T. G. Tachovsky. 1984. Association of CSF IgG concentration and immunoglobulin allotype in multiple sclerosis and optic neuritis. Clin. Immunol. Immunopath. 31:212-221.

60. Bulman, D. E., J. P. Pandey, and G. C. Ebers. 1987. Gm allotypes in multiple sclerosis. In Cellular and Humoral Immunological Components of Cerebrospinal Fluid in Multiple Sclerosis. A. Lowenthal and J. Raus, editors. Plenum Publishing Co. 81-86.

61. Haile, R. W. C., A. Goldstein, L. Field, and M. L. Marazita. 1985. A linkage analysis of the $\mathrm{Gm}$ locus and multiple sclerosis. Genet. Epidemiol. 2:29 34.

62. Seboue, R., M. Daveau, J. D. Degos, C. Martin-Mondiere, J. M. Goust, E. Schuller, L. Rivat-Peran, A. Coquerel, M. Dujardin, and J. P. Salier. 1985. IgG $(\mathrm{Gm})$ allotypes and multiple sclerosis in a French population: phenotype distribution and quantitative abnormalities in CSF with respect to sex, disease severity, and presence of intrathecal antibodies. Clin. Immunol. Immunopath. 37:143153.

63. Dersimonian, H., R. S. Schwartz, K. J. Barrett, and B. D. Stollar. 1987. Relationship of human variable region heavy chain germ-line genes to genes encoding anti-DNA antibodies. J. Immunol. 139:2496-2501.

64. Logtenberg, T., F. M. Young, J. H. Van Es, F. H. J. Gmelig-Meyling, and F. W. Alt. 1989. Autoantibodies encodied by the most JH proximal human immunoglobulin heavy chain variable region gene. J. Exp. Med. 170:1347-1355.

65. Crowley, J. J., R. A. Mageed, G. J. Silverman, P. P. Chen, F. Kozin, R. A Erger, R. Jefferis, and D. A. Carson. 1990. The incidence of a new human crossreactive idiotype linked to subgroup $\mathrm{V}_{\mathrm{H}} \mathrm{III}$ heavy chains. Hum. Immunol. 27:8794.

66. Chen, P. P., M.-F. Liu, S. Sinha, and D. A. Carson. 1988. A 16/6 idiotype positive anti-DNA antibody is encoded by a conserved VH gene with no somatic mutation. Arthritis Rheumat. 31:1429-1431.

67. Spatz, L. A., K. K. Wong, M. Williams, R. Desai, J. Golier, J. E. Bermann, F. W. Alt, and N. Latov. 1990. Cloning and sequence analysis of the $V_{H}$ and $V_{L}$ regions of an anti-myelin/DNA antibody from a patient with peripheral neuropathy and chronic lymphocytic leukemia. J. Immunol. 144:2821-2828.

68. Cuisinier, A.-M., V. Guigou, L. Boubli, M. Fougereau, and C. Tonnelle 1989. Preferential expression of VH5 and VH6 immunoglobulin genes in early human B-cell ontogeny. Scand. J. Immunol. 30:493-397.

69. Jeong H. D., and J. M. Teale. 1989. VH gene family repertoire of resting B cells. J. Immunol. 143:2752-2760.

70. Malynn, B. A., G. D. Yancopoulos, J. E. Barth, C. A. Bona, and F. W. Alt. 1990. Biased expression of $J_{H}$-proximal $V_{H}$ genes occurs in the newly generated repertoire of neonatal and adult mice. J. Exp. Med. 171:843-859.

71. Painter, C., M. Monestier, B. Bonin, and C. A. Bona. 1986. Functional and molecular studies of $\mathrm{V}$ genes expressed in autoantibodies. Immunol. Rev. 94:75-98. 